\title{
Inhibitive effect of Artemisia Judaica Herbs extract on the corrosion of carbon steel in hydrochloric acid solutions
}

\author{
A.S. Fouda, ${ }^{1}$ H.M. El-Abbasy ${ }^{2}$ and A.A. El-Sherbini ${ }^{1}$ \\ ${ }^{1}$ Chemistry Department, Faculty of Science, Mansoura University, \\ Mansoura-35516, Egypt \\ E-mail: asfouda@hotmail.com; asfouda@mans.edu.eg \\ ${ }^{2}$ Misr Higher Institute for Engineering and Technology, Mansoura, Egypt \\ E-mail: helabbasy@hotmail.com
}

\begin{abstract}
Artemisia Judaica herb extract (AJH) was tested as an eco-friendly corrosion protection of carbon steel (CS) in $1.0 \mathrm{M}$ hydrochloric acid as attacking medium utilizing non electrochemical methods (mass reduction (MR)), and electrochemical methods such as (EIS) AC electrochemical impedance spectroscopy, and (PP) Tafel polarization tests. The obtained data revealed that the protective efficiency increased with increasing extract dose and also increased with increasing temperature. Surface examination was performed by (AFM) atomic force microscope (in order to determine the degree of roughness of the CS surface), (SEM) scanning electron microscope (in order to determine the film formed on CS surface) and (FT-IR) Fourier transforms infrared spectroscopy (in order to determine the adsorbed groups on CS surface). These tests revealed that the extract molecules form a film on CS surface. The AJH extract was adsorbed physically and spontaneously on CS surface and follows Langmuir's isotherm. The adsorption $\left(K_{\text {ads }}, \Delta H_{\text {ads }}^{0}, \Delta G_{\text {ads }}^{0}\right)$ factors were calculated using adsorption isotherm, and activation $\left(E_{\mathrm{a}}^{*}, \Delta H^{*}, \Delta S^{*}\right)$ parameters were determined from Arrhenius and transition state theories and debated. Polarization data revealed that this extract is mixed type one, i.e. affects both anodic metal dissolution and cathodic hydrogen evolution. EIS data revealed that the charge transfer resistance $\left(R_{\mathrm{ct}}\right)$ increased, on the other hand the capacitance double layer $\left(C_{\mathrm{dl}}\right)$ decreased in the presence of AJH extract. Toxicity of the extract was determined by Microtox Model 500 analyzer. Different components in the extract were dedicated by HPLC apparatus. Quantum chemical calculations were performed using Materials Studio 7.0 software and discussed for five main components in the extract.

Received: January 17, 2018. Published: June 6, 2018

doi: $\underline{10.17675 / 2305-6894-2018-7-2-8}$

Keywords: corrosion mitigation, CS, HCl, Artemisia Judaica herb extract, FTIR, AFM, HPLC.
\end{abstract}




\section{Introduction}

Corrosion is dangerous for economics and safety of alloys particularly. The usage of inhibitors is the best one of the very most workable options for corrosion controlling process, specifically in acidic solution [1]. Maximum utilized inhibitors in the industry are natural and organic composites including oxygen, sulfur and nitrogen atoms. Inhibitors containing double or triple bonds assume a critical part in encouraging the adsorption of the mixes onto metal surfaces [2]. There is an interaction between electron pairs and/or the cloud of $\pi$-electron for donor atoms and the metallic surface, therefore lowering the attack of corrosive materials in the corrosion solution. Several compounds are incredibly toxic to humans, have an awful environmental effect and its own high-cost [3]. Plant extracts are cheap and ecologically safe, so the key features of utilizing extracts as corrosion mitigation is money related and safe condition. As of late, many extracts have been utilized as viable corrosion mitigation for CS or/and different metals in acid solutions, such as Zenthoxylum alatum [4], Anise [5], Propolis [6], orange peels [7], Myrtus communis [8], Azadirachta indica [9], fruit peel [10] and Vernonia amygdalina [11]. The protection of extracts is regularly attributed to the attendance of a complex of organic compounds [12] containing flavonoids, polyphenols, nitrogen, alkaloids bases [13], proteins, amino acids [14] and sugars not only that but also possible hydrolysis molecules in their structure. These organic and natural products as a rule hold polar utilities with donor atoms [15] not only, but also have conjugated or aromatic rings or triple double bonds in assemblies, which are found largely in adsorption sites.

The scope of this paper is to: i) study the inhibition efficiency of AJH on CS corrosion in acidic solution through chemical and electrochemical studies, ii) analyze the surface of the metal to confirm the adsorption of the extract through the AFM, SEM and FT-IR examinations [16] and also iii) to calculate some quantum chemical parameters of the main components in the extract.

\section{Methodology}

\subsection{Raw materials and acid solutions}

The desired tests utilized CS of kind 1018. The corrosive solution was prepared from $36.5-38 \%$ hydrochloric acid by dilution with bidistilled water to prepare a $1.0 \mathrm{M}$ solution. Solution of AJH was prepared to give $1000 \mathrm{ppm}$ as a stock solution, then, diluted by bidistilled water to obtain different doses, as needed for studying the inhibition activity of the AJH.

\subsection{Readying of $A J H$}

The utilized sections were the leaves of AJH. The specimens were collected from Saint Catherine, South Sinai, Egypt. The leaves were crushed to give $500 \mathrm{~g}$ of a powder. An 
identified quantity of powder material was soxholated. Finally, the concentrate was collected, weighed, put at $4^{\circ} \mathrm{C}$ and kept for utilizing when required [17].

\subsection{Toxicity}

Microtox Model 500 analyzer for fast toxicity discovery is an in vitro assessment system, which utilizes bioluminescent bacteria (Vibrio fischeri) for the toxicity acknowledgement. It was utilized as a screening method to perceive the qualified toxicity of a taster. All Microtox values were verified and calculated by on-line software and the outcome was communicated as the Operational dose, $50 \%$ (EC50) in the presence of extract $/ 2 \mathrm{~g} \mathrm{AJH}$ extract. TU (Toxicity Unit) was computed using the following equation [18]:

$$
\mathrm{TU}=(1 / \mathrm{EC} 50) \times 100 \%
$$

The TU is unitless. The great TU data specifies maximum toxicity. Nevertheless, TU is comparative toxicity categorized into four groups as Table 1:

Table 1. Toxicity unit range

\begin{tabular}{ccc}
\hline TU & Toxicity \\
\hline$<1$ & Non toxic \\
$1-10$ & Toxic \\
$10-100$ & Very Toxic \\
$>100$ & Extremely Toxic \\
\hline
\end{tabular}

\subsection{High performance liquid chromatography (HPLC)}

Components such as Phenolic [19] and Flavonoids [20] have detected by HPLC apparatus. $5 \mathrm{~g}$ of the extract were dissolved in methanol and centrifuged at 10,000 rpm for $60 \mathrm{sec}$. The supernatant was filtered over a 0.2 micrometer Millipore membrane filter, at that point $0.1-0.3 \mathrm{~cm}$ was assembled in a vial for admission into an HPLC TR column. The temperature of the column was kept up at $35^{\circ} \mathrm{C}$. To estimate phenolic and flavonoids Hewlett Packard programming was used.

\subsection{Electrochemical measurements}

The cell of a Gamry apparatus (PCI4/750) Potentiostat/Galvanostat/ZRA [21] consists of three electrodes, CS as a working electrode, a platinum wire as a counter electrode and a SCE reference electrode. Before measurement, the CS was allowed to stabilize for $30 \mathrm{~min}$ before starting the tests. Tafel polarization curves were recorded by changing the electrode potential from -1.5 to $0.5 \mathrm{~V} v s$. OCP at a scan rate of $1.0 \mathrm{mV} \mathrm{s}^{-1}$. The EIS tests were performed in the frequency range of $10^{5} \mathrm{~Hz}-0.01 \mathrm{~Hz}$ at the OCP using AC signals of amplitude $5 \mathrm{mV}$. Electrochemical frequency modulation (EFM) was performed utilizing two frequencies 2 and $5 \mathrm{~Hz}$ and the base frequency was $0.1 \mathrm{~Hz}$. 


\subsection{Mass reduction (MR) experiment}

The MR is likely the most generally utilized technique for corrosion studies [22, 23]. The specimens were immersed in $100 \mathrm{ml}$ beakers with $1.0 \mathrm{M} \mathrm{HCl}$ in addition to several doses of $\mathrm{AJH}$ at temperatures between $25-45^{\circ} \mathrm{C}$. After different periods (30 min to $180 \mathrm{~min}$ each), the CS coins were taken away from the solution, washed, air dried and weighed again. The mass reduction was obtained to calculate the corrosion rate (C.R). The protection efficiency (\%IE) and the surface coverage $(\theta)$ were calculated also.

\subsection{Surface Morphology}

\subsubsection{AFM test}

The analysis of the CS surface was carried out using (AFM). The CS coins were scraped with emery papers from 220-1500 and gave ultra-smooth surfaces. After immersion in $1.0 \mathrm{M} \mathrm{HCl}$ in the presence or absence of $300 \mathrm{ppm} \mathrm{AJH}$ extract at $25.0^{\circ} \mathrm{C}$ for $6 \mathrm{~h}$, the coins were washed with bidistilled water, dried with a jet of air [24] and then used for analysis. The model Wet-SPM (Scanning Probe microscope) Shimadzu made in Japan was utilized for AFM tests.

\subsubsection{FT-IR spectroscopy analysis}

The CS specimen $(2 \times 2 \mathrm{~cm})$ was dipped in $1.0 \mathrm{M} \mathrm{HCl}$ and $300 \mathrm{ppm} \mathrm{AJH}$ for 6 hours and then examined directly by FT-IR spectra (ATR-IR Affinity-1, Shimadzu, Japan). But firstly [25], CS specimen was scraped with different grades of emery papers from rough to smooth, washed with water and acetone, finally dried out in the air and then examined by the instrument [26].

\subsubsection{SEM test}

The morphology of CS surface unprotected and protected was tested utilizing JEOL JSM6510 Microscope [27].

\subsection{Quantum chemical studies}

Quantum chemical calculations were executed to the main constituent of the AJH extract by using Materials Studio 7.0 software [28, 29]. The information about the electron distributions of the five main constituents (Naringin, Ellagic acid, Piperitone, Bronyl acetate, Terpinen-4-ol) can be calculated by density functional theory (DFT). The DFT calculations were conducted with DMol3 module code [30]. 


\section{Results and Discussion}

\subsection{Toxicity}

By examining the toxicity of the AJH extract, it was found that it was not poisonous due to that the TU was less than 1 as appeared in Table 2.

Table 2. Toxicity unit of the AJH extract.

\begin{tabular}{ccc}
\hline Extract & TU & Toxicity \\
\hline AJH & $<1$ & Non toxic \\
\hline
\end{tabular}

\subsection{HPLC}

Phenolic and Flavonoids compounds were detected by HPLC and are listed below: Naringin $\left(\mathrm{C}_{27} \mathrm{H}_{32} \mathrm{O}_{14}\right)$, Apigenin $\left(\mathrm{C}_{15} \mathrm{H}_{10} \mathrm{O}_{5}\right)$, Acacetin $\left(\mathrm{C}_{16} \mathrm{H}_{12} \mathrm{O}_{5}\right)$, Pyrogallol $\left(\mathrm{C}_{6} \mathrm{H}_{6} \mathrm{O}_{3}\right)$, 4aminobenzoic acid $\left(\mathrm{C}_{7} \mathrm{H}_{7} \mathrm{NO}_{2}\right)$, Chlorogenic acid $\left(\mathrm{C}_{16} \mathrm{H}_{18} \mathrm{O}_{9}\right)$, Vanillic acid $\left(\mathrm{C}_{8} \mathrm{H}_{8} \mathrm{O}_{4}\right)$, Ellagic acid $\left(\mathrm{C}_{14} \mathrm{H}_{6} \mathrm{O}_{8}\right)$, Benzoic acid $\left(\mathrm{C}_{7} \mathrm{H}_{6} \mathrm{O}_{2}\right)$, Isoferulic acid $\left(\mathrm{C}_{10} \mathrm{H}_{10} \mathrm{O}_{4}\right)$.

AJH contains another ingredients beside Phenolic and Flavonoids compounds, but also contains essential oils and other ingredients from reviewing alternate researches [31] such as Piperitone $\left(\mathrm{C}_{10} \mathrm{H}_{16} \mathrm{O}\right)$, Terpinen-4-ol $\left(\mathrm{C}_{10} \mathrm{H}_{18} \mathrm{O}\right)$ and Bronyl acetate.

\subsection{Electrochemical measurements}

\subsubsection{PP curves}

$\mathrm{PP}$ curves for the corrosion of $\mathrm{CS}$ in $1.0 \mathrm{M} \mathrm{HCl}$ in the existence and nonexistence of several doses of $\mathrm{AJH}$ at $25.0^{\circ} \mathrm{C}$ are shown in Figure 1 . The results obtained for the electrochemical parameters of various doses of $\mathrm{AJH}$ extract are reported in Table 3. The obtained data showed that the cathodic and anodic diagrams were shifted to more negative and more positive values, correspondingly. The AJH extract can acts as a mixed inhibitor [32], because the AJH molecules are adsorbed over the surface of CS and protect both the hydrogen evolution $2 \mathrm{H}^{+}{ }_{(\mathrm{aq})}+2 \mathrm{e}^{-} \rightarrow \mathrm{H}_{2(\mathrm{~g})}$ and iron dissolution $\mathrm{Fe}_{(\mathrm{s})} \rightarrow \mathrm{Fe}^{2+}(\mathrm{aq})+2 \mathrm{e}^{-}$ reactions [33]. Table 3 showed the values of anodic $\left(b_{a}\right)$ and cathodic $\left(b_{c}\right)$ Tafel slopes. As shown, they are almost unaltered, causing a nearly parallel set of anodic and cathodic lines. Thus, the adsorbed extract molecules decrease the surface area for corrosion without having an effect on the corrosion mechanism of CS in such solutions, but on the other hand a part of the surface is deactivated with respect to the corrosive medium [34]. The \%IE at various doses $(50-300 \mathrm{ppm})$ reached $69 \%$ to $87 \%$ and $\left(i_{\text {corr }}\right)$ decreases from $205 \mathrm{~mA} / \mathrm{cm}^{2}$ to $27.30 \mathrm{~mA} / \mathrm{cm}^{2}$, and the C.R changed from 93.86 to $12 \mathrm{mpy}$. This is because of the great coverage of the metal surface by AJH molecules which hindered the dissolution reaction of the metal. \%IE and $\theta$ were calculated using Equation (2):

$$
\% \mathrm{IE}=\left[1-\left(i_{\text {corr }}^{0} / i_{\text {corr }}\right)\right] \times 100
$$


Where $i_{\text {corr }}^{0}$ and $i_{\text {corr }}$ are the currents without and with the existence of $\mathrm{AJH}$, respectively.

The relationship $\theta=\left[1-\left(i_{\text {corr }}^{0} / i_{\text {corr }}\right)\right]$ follows from the assumption that the inhibitor acts by the blocking mechanism.

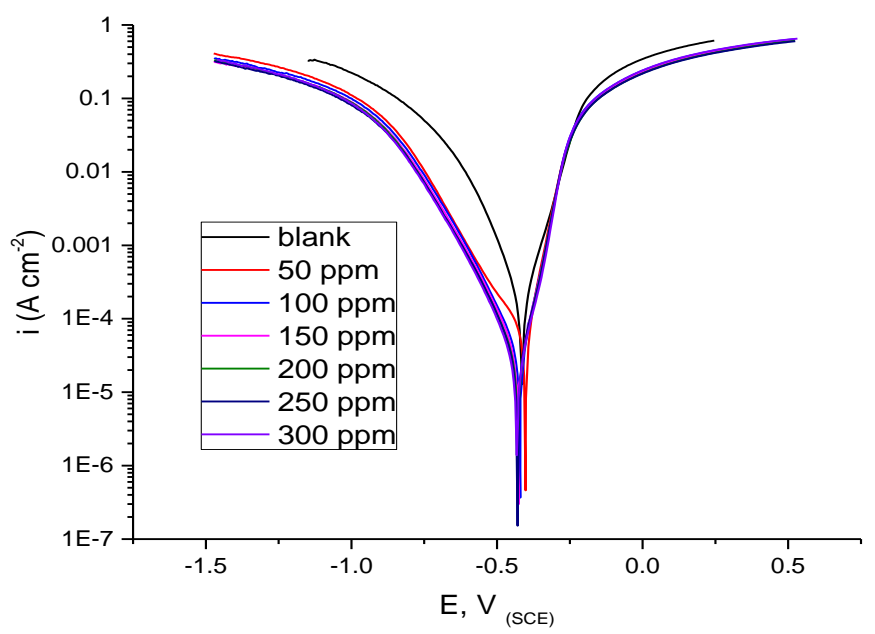

Figure 1. PP curves for the corrosion of CS with and without several doses of $\mathrm{AJH}$ at $25.0^{\circ} \mathrm{C}$.

Table 3. Parameters obtained from PP for the corrosion of CS with and without several doses of AJH at $25^{\circ} \mathrm{C}$.

\begin{tabular}{|c|c|c|c|c|c|c|c|}
\hline $\begin{array}{c}{[\text { Inh.] }} \\
\text { ppm }\end{array}$ & $\begin{array}{c}-E_{\text {corr }} \\
\mathrm{mV} v \boldsymbol{v s .} \text { SCE }\end{array}$ & $\begin{array}{c}i_{\text {corr }} \\
\mu \mathrm{A} \mathrm{cm}^{-2}\end{array}$ & $\begin{array}{c}b_{\mathrm{c}} \\
\mathrm{mV} \operatorname{dec}^{-1}\end{array}$ & $\begin{array}{c}b_{\mathrm{a}} \\
\mathrm{mV} \operatorname{dec}^{-1}\end{array}$ & $\begin{array}{l}\text { C.R } \\
\text { Mpy }\end{array}$ & $\theta$ & $\%$ IE \\
\hline Blank & 414 & 205 & 120 & 83 & 93.86 & - & - \\
\hline 50 & 402 & 63.2 & 161 & 59 & 28.87 & 0.692 & 69.2 \\
\hline 100 & 420 & 46.9 & 152 & 64 & 21.44 & 0.771 & 77.1 \\
\hline 150 & 426 & 37.8 & 149 & 65.4 & 17.27 & 0.816 & 81.6 \\
\hline 200 & 427 & 32.5 & 140 & 69.9 & 14.91 & 0.841 & 84.1 \\
\hline 250 & 430 & 31.5 & 137.6 & 64.8 & 14.41 & 0.846 & 84.6 \\
\hline 300 & 431 & 27.30 & 137 & 65.10 & 12.0 & 0.867 & 86.7 \\
\hline
\end{tabular}

\subsubsection{Analysis of AC impedance spectra}

Figures 2 demonstrate Nyquist diagrams, for CS in $1.0 \mathrm{M} \mathrm{HCl}$ as blank and in the presence of several doses of AJH extract (from 50 to $300 \mathrm{ppm}$ ) at $25^{\circ} \mathrm{C}$. The EIS was used to check the formation of protecting film on surface of CS [35]. The film formed on CS lowers double layer capacitance $\left(C_{\mathrm{dl}}\right)$ and rises the charge transfer resistance $\left(R_{\mathrm{ct}}\right)$. EIS parameters such as $R_{\mathrm{ct}}, C_{\mathrm{dl}}$ are given in Table 4 . Figure 3 represents the Bode plot which showed one time constant, at moderate frequencies. The increasing in the diameter of the semicircles 
with the existence of AJH extract may be due to the accumulation of $\mathrm{AJH}$ molecules on the surface area of electrode. There is only one phase maximum in Bode plot (Figure 3), and this appears only one relaxation process. This can be assigned to the charge transfer process, which occurred between the metal surface and electrolyte [36]. The $C_{\mathrm{dl}}$ values were estimated from phase element CPE circuit (Figure 4), and calculated from by Equation (3) [37]:

$$
C_{\mathrm{dl}}=Y^{0}\left(\omega_{\max }\right)^{n-1}
$$

The \%IE and $(\theta)$ were obtained from the EIS test utilizing the following Equation 4 [38]:

$$
\% \mathrm{IE}=100 \times \theta=\left[1-\left(R_{\mathrm{ct}}^{0} / R_{\mathrm{ct}}\right)\right] \times 100
$$

Where $R_{\mathrm{ct}}^{0}$ and $R_{\mathrm{ct}}$ are the resistances in the inhibited and uninhibited metal, correspondingly.

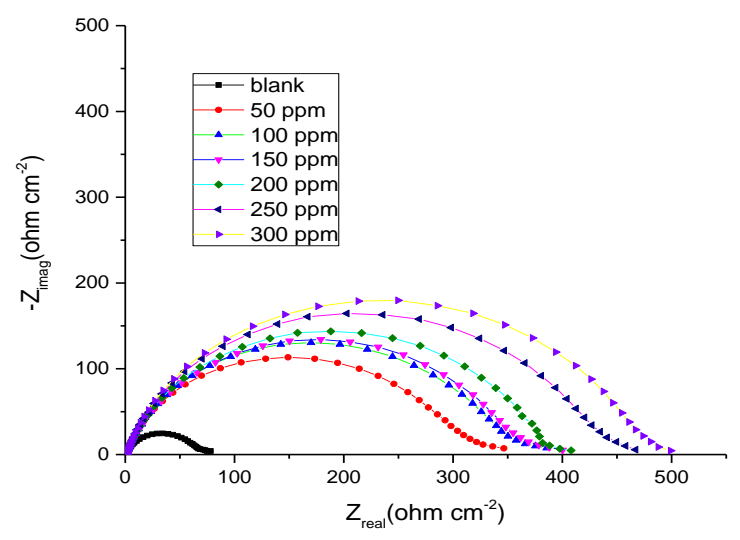

Figure 2. Nyquist diagrams for $\mathrm{CS}$ in $1.0 \mathrm{M} \mathrm{HCl}$ and several doses of $\mathrm{AJH}$ at $25^{\circ} \mathrm{C}$.

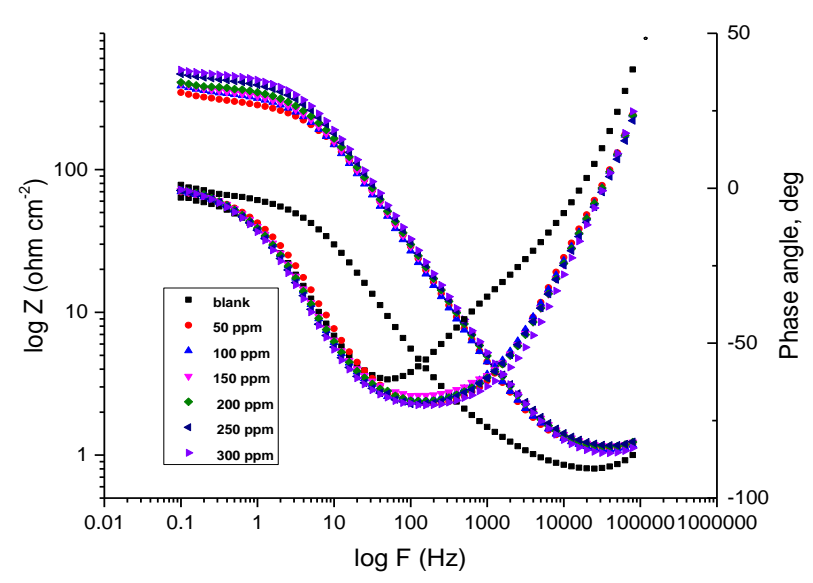

Figure 3. Bode diagrams for $\mathrm{CS}$ in $1.0 \mathrm{M} \mathrm{HCl}$ with and without several doses of $\mathrm{AJH}$ at $25^{\circ} \mathrm{C}$. 
Table 4. Parameters given from EIS tests for the corrosion of CS with and without several doses of AJH at $25^{\circ} \mathrm{C}$.

\begin{tabular}{ccccc}
\hline [Inh], ppm & $\boldsymbol{C}_{\mathbf{d l},}, \boldsymbol{\mu} \mathbf{F c m}{ }^{-2}$ & $\boldsymbol{R}_{\mathbf{c t}}, \boldsymbol{\Omega} \mathbf{~ c m}^{\mathbf{2}}$ & $\boldsymbol{\theta}$ & $\boldsymbol{\%} \mathbf{I E}$ \\
\hline Blank & 539 & 70 & - & - \\
50 & 83 & 306 & 0.771 & 77.1 \\
100 & 96 & 351 & 0.801 & 80.1 \\
150 & 90 & 362 & 0.807 & 80.7 \\
200 & 85 & 381 & 0.816 & 81.6 \\
250 & 81 & 435 & 0.829 & 82.9 \\
300 & 77 & 469 & 0.885 & 88.5 \\
\hline
\end{tabular}

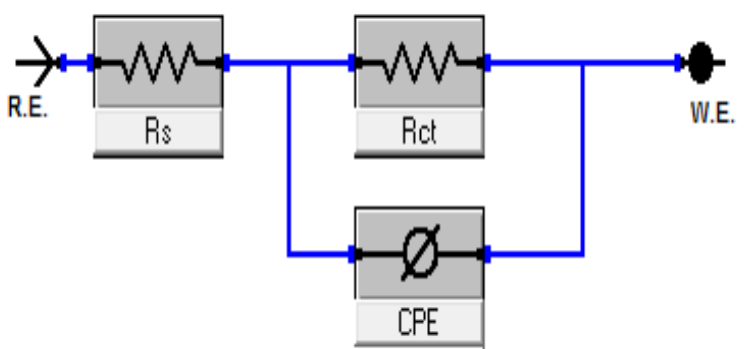

Figure 4. Equivalent circuit utilized to fit the EIS values.

The calculated items like $R_{\mathrm{s}}, R_{\mathrm{ct}}, C_{\mathrm{dl}}$ and \%IE from EIS data are recorded in Table 4. EIS data revealed that $R_{\mathrm{ct}}$ values increase and the $C_{\mathrm{dl}}$ values decrease as the extract doses increase. The decrease in the $C_{\mathrm{dl}}$ caused by the gradual replacement of water molecules by the adsorption of the extract molecules on the metal surface, and decreasing the local dielectric constant and/ or from the increase thickness of the electrical double layer [39], suggesting that the extract molecules function by adsorption at the metal/solution interface. The high $R_{\mathrm{ct}}$ values generally correlate with a slower corroding system.

\subsection{MR measurements}

The results of the addition of various doses (50-300 ppm) of the AJH extract on the CS dissolution in $1.0 \mathrm{M} \mathrm{HCl}$ solution were determined by MR. The MR test was utilized to calculate corrosion rates (C.R) and IE.

Figure 5 demonstrates the relation between various doses of $\mathrm{AJH}$ on the MR of CS versus time at $25^{\circ} \mathrm{C}$. Clearly, the MR of CS in the presence of AJH was much less than that acquired in blank solution, the higher dose of AJH the higher \% IE. 


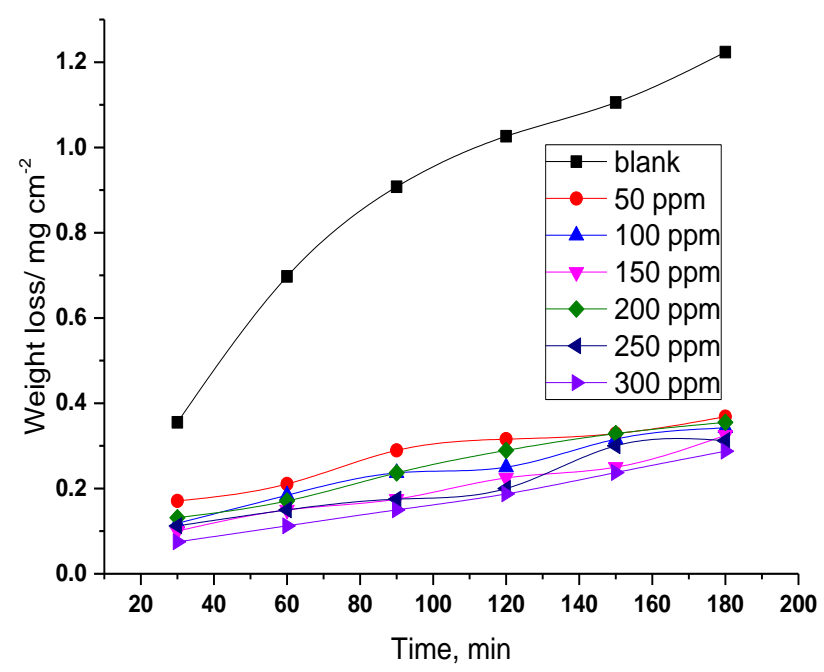

Figure 5. Effect of increasing doses of $\mathrm{AJH}$ on $\mathrm{MR}$ for $\mathrm{CS}$ corrosion in $1.0 \mathrm{M} \mathrm{HCl}$ at $25^{\circ} \mathrm{C}$.

\subsubsection{Effect of temperature}

The effect of various temperatures $\left(25,30,35,40\right.$ and $\left.45^{\circ} \mathrm{C}\right)$ on dissolution of $\mathrm{CS}$ in the presence and absence of various doses of $\mathrm{AJH}$ was examined by MR tests. \%IE and $\theta$ were calculated using Equation (5):

$$
\% \mathrm{IE}=\left[\left(W_{0}-W_{\mathrm{i}}\right) / W_{0}\right] \times 100=\theta \times 100
$$

Where $W_{0}$ and $W_{\mathrm{i}}$ are the MR in the nonexistence and existence of the $\mathrm{AJH}$, correspondingly.

The estimations of C.R and \%IE obtained from the MR tests for various doses of AJH in $1.0 \mathrm{M} \mathrm{HCl}$ solution at several temperatures appear in Table 5. The results demonstrate that the more extract doses the less C.R value obtained and consequently increase of \%IE. This is because of the way that the degree of adsorption and the resultant coverage by extract on CS surface increases with the extract dose [40] as observed in Table 5.

Table 5. Data from MR of CS for various doses of AJH after $120 \mathrm{~min}$ immersion at different temperatures.

\begin{tabular}{ccccc}
\hline Temp, ${ }^{\circ} \mathbf{C}$ & {$[\mathbf{I n h}], \mathbf{p p m}$} & $\boldsymbol{\theta}$ & $\boldsymbol{\%} \mathbf{I E}$ & $\begin{array}{c}\mathbf{C . R}, \\
\mathbf{m g ~ c m}^{-\mathbf{2}} \mathbf{m i n}^{\mathbf{- 1}}\end{array}$ \\
\hline & Blank & - & - & 0.0086 \\
25 & 50 & 0.692 & 69.2 & 0.0026 \\
& 100 & 0.756 & 75.6 & 0.0021 \\
& 150 & 0.781 & 78.1 & 0.0019 \\
& 200 & 0.718 & 71.8 & 0.0024 \\
250 & 0.805 & 80.5 & 0.0017 \\
& 300 & 0.817 & 81.7 & 0.0016 \\
\hline
\end{tabular}




\begin{tabular}{|c|c|c|c|c|}
\hline Temp, ${ }^{\circ} \mathbf{C}$ & {$[\mathbf{I n h}], \mathbf{p p m}$} & $\theta$ & $\%$ IE & $\underset{\mathrm{mg} \mathrm{cm}^{-2} \min ^{-1}}{\text { C.R, }}$ \\
\hline \multirow{7}{*}{30} & Blank & - & - & 0.0161 \\
\hline & 50 & 0.829 & 82.9 & 0.0027 \\
\hline & 100 & 0.850 & 85.0 & 0.0024 \\
\hline & 150 & 0.838 & 83.8 & 0.0026 \\
\hline & 200 & 0.830 & 83.0 & 0.0027 \\
\hline & 250 & 0.864 & 86.4 & 0.0022 \\
\hline & 300 & 0.871 & 87.1 & 0.0021 \\
\hline \multirow{7}{*}{35} & Blank & - & - & 0.0313 \\
\hline & 50 & 0.888 & 88.8 & 0.0035 \\
\hline & 100 & 0.891 & 89.1 & 0.0034 \\
\hline & 150 & 0.893 & 89.3 & 0.0033 \\
\hline & 200 & 0.909 & 90.9 & 0.0029 \\
\hline & 250 & 0.919 & 91.9 & 0.0025 \\
\hline & 300 & 0.927 & 92.7 & 0.0023 \\
\hline \multirow{7}{*}{40} & Blank & - & - & 0.0396 \\
\hline & 50 & 0.898 & 89.8 & 0.0040 \\
\hline & 100 & 0.903 & 90.3 & 0.0038 \\
\hline & 150 & 0.909 & 90.9 & 0.0036 \\
\hline & 200 & 0.903 & 90.3 & 0.0038 \\
\hline & 250 & 0.930 & 93.0 & 0.0032 \\
\hline & 300 & 0.926 & 92.6 & 0.0029 \\
\hline \multirow{7}{*}{45} & Blank & - & - & 0.0634 \\
\hline & 50 & 0.909 & 90.9 & 0.0058 \\
\hline & 100 & 0.915 & 91.5 & 0.0054 \\
\hline & 150 & 0.920 & 92.0 & 0.0050 \\
\hline & 200 & 0.927 & 92.7 & 0.0046 \\
\hline & 250 & 0.920 & 92.0 & 0.0050 \\
\hline & 300 & 0.929 & 92.9 & 0.0045 \\
\hline
\end{tabular}


The estimation of $E_{\mathrm{a}}^{*}$ was computed by Arrhenius equation (6):

$$
\log \text { C.R. }=-E_{\mathrm{a}}^{*} / 2.303 R T+\log A
$$

where, $A$ is the Arrhenius pre-exponential multiplier. The plots of log C.R against 1/T without and with various doses of $\mathrm{AJH}$ gave straight lines (Figure 6). The estimations of $E_{\mathrm{a}}^{*}$ were computed from the straight line slopes:

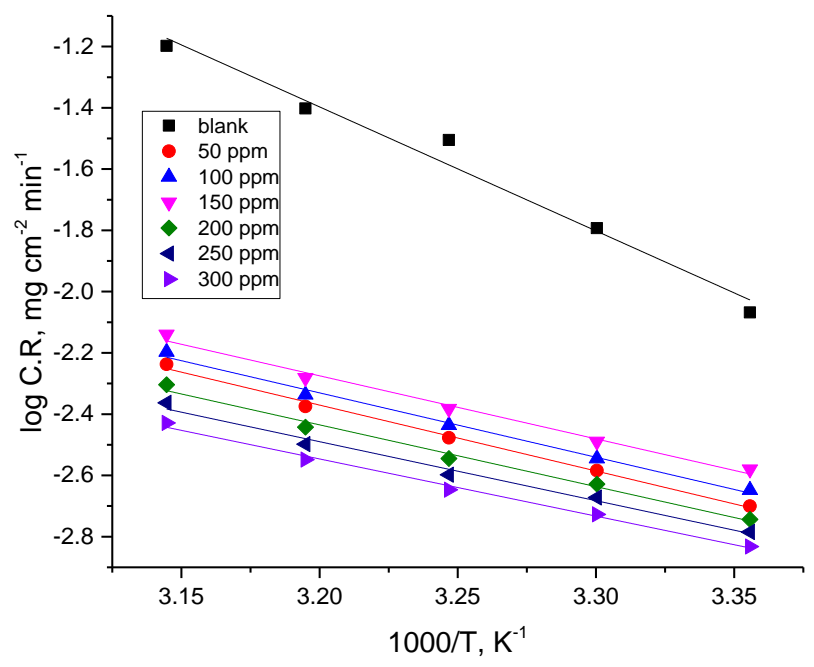

Figure 6. Arrhenius diagrams for CS dissolution with and without various doses of AJH.

The enthalpy $\left(\Delta H^{*}\right)$ and entropy $\left(\Delta S^{*}\right)$ of activation for the dissolution of CS were computed using the next equation (7):

$$
\text { C.R }=R T / N h \exp \left(\Delta S^{*} / R\right) \exp \left(-\Delta H^{*} / R T\right)
$$

where $N$ is Avogadro's number and $h$ is Planck's constant. The plots of (1/T) versus $\log (C R / T)$ gave straight lines (Figure 7) where the slope is $\left(-\Delta H^{*} / 2.303 R\right)$ and the intercept is $\left[\left(\log (R / N h)+\left(\Delta S^{*} / 2.303 R\right)\right)\right]$.

The calculated data of $E_{\mathrm{a}}^{*}, \Delta H^{*}$ and $\Delta S^{*}$ obtained with or without the presence of the extract are privided in Table 6 . From Table 6 , we can conclude that the values of activation energy in the presence of the extract are lower than that in its absence. The negative values of $\Delta S^{*}$ indicate that the activated complex within the rate determining step indicates an association rather than dissociation step, implying that disorder happens over the path of transition from reactant to the activated complex [41]. The negative sign of $\Delta H^{*}$ offers that the $\mathrm{AJH}$ molecules are adsorbed endothermically on metal surface. 


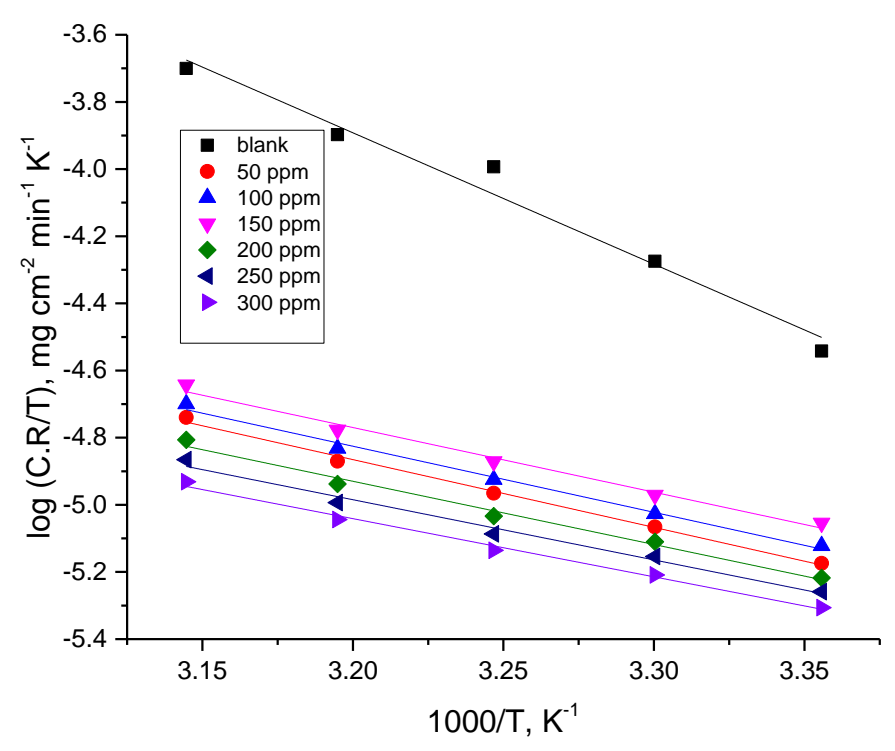

Figure 7. Plots of $\log$ C.R/T vs. 1000/T for CS with and without various doses of AJH.

Table 6. Values of $\mathrm{E}_{\mathrm{a}}^{*}, \Delta H^{*}$ and $\Delta S^{*}$ for the protection process.

\begin{tabular}{|c|c|c|c|}
\hline [Inh], ppm & $E_{\mathrm{a}}^{*}, \mathbf{k J ~ \mathbf { m o l } ^ { - 1 }}$ & $\Delta H^{*}, \mathbf{k J} \mathrm{mol}^{-1}$ & $-\Delta S^{*}, \mathrm{~J} \mathrm{~mol}^{-1} \mathrm{~K}^{-1}$ \\
\hline Blank & 77.5 & 74.9 & 32.2 \\
\hline 50 & 41.2 & 38.6 & 167.1 \\
\hline 100 & 40.2 & 37.7 & 169.3 \\
\hline 150 & 39.4 & 36.8 & 170.9 \\
\hline 200 & 28.6 & 36.0 & 176.5 \\
\hline 250 & 36.9 & 34.3 & 183.1 \\
\hline 300 & 35.7 & 33.2 & 187.8 \\
\hline
\end{tabular}

\subsubsection{Adsorption isotherms}

Some data are required for the corrosion mechanism; these data were obtained from the investigation of adsorption isotherms. Applying the different adsorption isotherms, the most appropriate isotherm that fits the results is the Langmuir adsorption isotherm equation. As indicated by this isotherm, the part of CS surface protected with the inhibitor, $\theta$, is determined by the inhibitor dose, $C$, by Eq. (8):

$$
C / \theta=1 / K_{\text {ads }}+C
$$

Where $K_{\text {ads }}$ refers to the adsorption equilibrium constant for the adsorption-desorption process. The adsorption process may be seen as condensation while desorption as evaporation of the adsorbate molecules with respect to the surface. This isotherm assumed i) a monolayer adsorption of adsorbate at fixed number of definite localized adsorption 
sites, ii) that there is no lateral interaction or steric hindrance between adsorbed molecules, and iii) all sites on the adsorbent have constant sorption and activation energy and enthalpy [42]. Straight lines were obtained by plotting Langmuir adsorption isotherm at various temperatures (with slopes almost equal to unity), as shown in Figure (8).

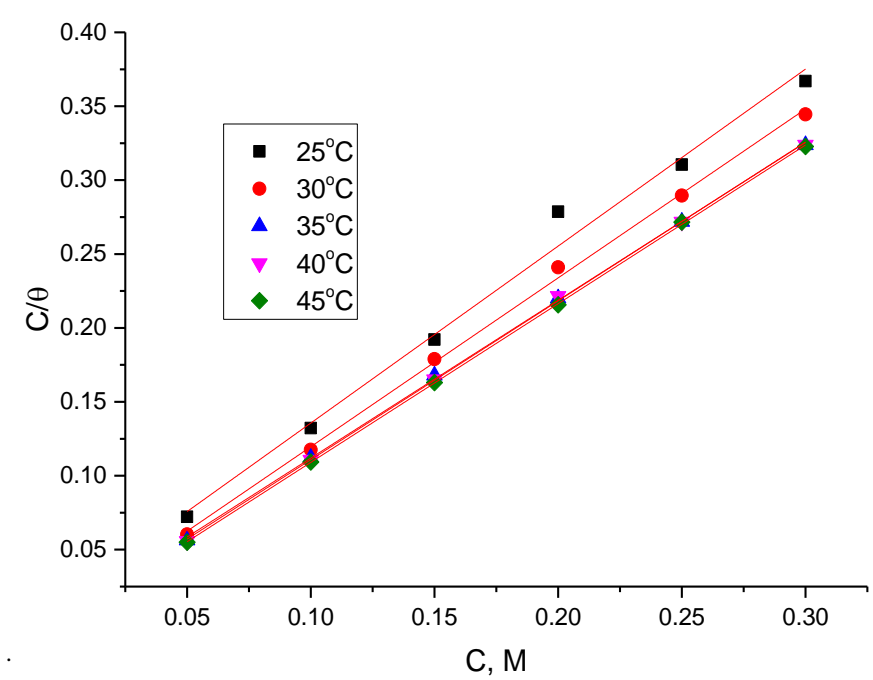

Figure 8. Langmuir adsorption isotherm for AJH extract on CS surface in $1.0 \mathrm{M} \mathrm{HCl}$ at various temperatures.

The assessment of equilibrium constant, $K_{\text {ads }}$ obtained from the reciprocal $\left(1 / K_{\text {ads }}\right)$ of the intercept on the ordinate of the Langmuir isotherm should increase with increase in temperature and strength of adsorption. The $\Delta G_{\text {ads }}^{0}$ values were obtained from Eq. (9):

$$
K_{\text {ads }}=1 / 55.5 \exp \left(-\Delta G_{\text {ads }}^{0} / R T\right)
$$

Where 55.5 refers to the dose of water in the bulk solution in $(\mathrm{mol} / \mathrm{L})$ at the interface of solution/metal. The computed values of $\Delta G_{\mathrm{ads}}^{0}$ are shown in Table 7. The $\Delta G_{\mathrm{ads}}^{0}$ had negative sign, which proposed that the adsorption procedure of AJH over CS surface is spontaneous one. For the data of $\Delta G_{\mathrm{ads}}^{0}$ around $\left(-20 \mathrm{~kJ} \mathrm{~mol}^{-1}\right)$ (physical adsorption) whilst those around $\left(-40 \mathrm{~kJ} \mathrm{~mol}^{-1}\right.$ ) (chemisorption) [43, 44]. For the situation of this review, the $\Delta G_{\text {ads }}^{0}$ values were confined between $20.2 \mathrm{~kJ} \mathrm{~mol}^{-1}$ and $27.5 \mathrm{~kJ} \mathrm{~mol}^{-1}$, this may show that both physical and chemical adsorption occurred [45]. The $\Delta H_{\text {ads }}^{0}$ was computed utilizing the Vant Hoff equation (10) [46]:

$$
\ln K_{\mathrm{ads}}=-\Delta H_{\mathrm{ads}}^{0} / R T+\text { constant }
$$

Figure (9) shows a plot $\log K_{\text {ads }}$ versus $1 / T$ for CS dissolution in acid in the existence of AJH. The $\Delta H_{\text {ads }}^{0}$ data (Table 7) are negative, which demonstrates that the adsorption is an exothermic process. Eventually, $\Delta S_{\text {ads }}^{0}$ can be calculated using Eq. (11): 


$$
\Delta S_{\mathrm{ads}}^{0}=\left(\Delta H_{\mathrm{ads}}^{0}-\Delta G_{\mathrm{ads}}^{0}\right) / T
$$

The calculated $\Delta S_{\text {ads }}^{0}$ values are listed in Table 7 . These calculated values imply that the adsorption process is characterized by a decrease in the entropy.

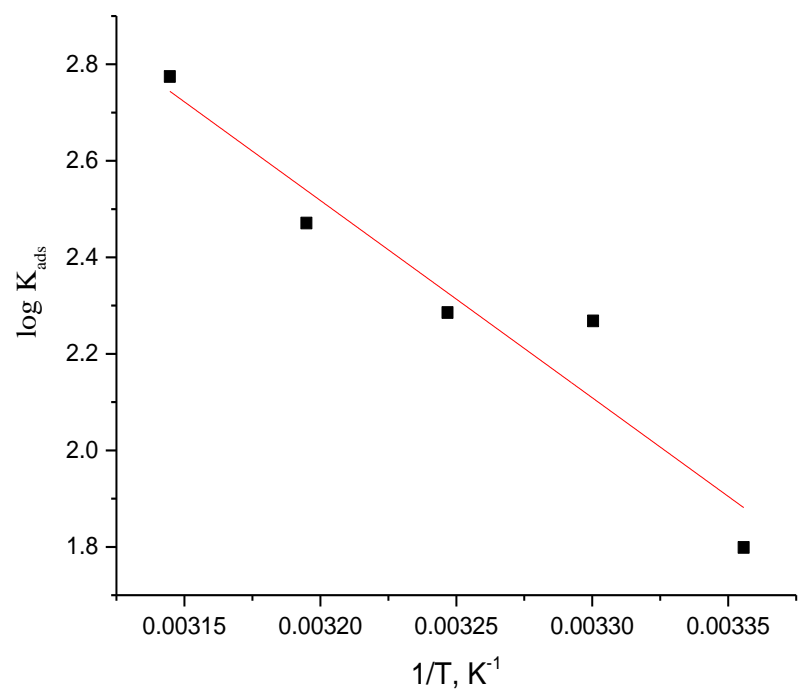

Figure 9. Plots of $\log K_{\text {ads }} v s .1 / T$ for dissolution of CS in $1 \mathrm{M} \mathrm{HCl}$.

Table 7. Langmuir adsorption parameters for AJH on CS surface after 120 min immersion at various temperatures.

\begin{tabular}{ccccc}
\hline Temp, ${ }^{\circ} \mathbf{C}$ & $\boldsymbol{K}_{\text {ads }}$ & $-\Delta G_{\text {ads }}^{0}$ & $-\Delta H_{\text {ads }}^{0}$ & $\Delta S_{\text {ads }}^{0}$ \\
\hline 25 & 62.9 & 20.2 & & 330.5 \\
30 & 185.5 & 23.3 & & 335.1 \\
35 & 193.1 & 23.8 & 78.3 & 331.3 \\
40 & 295.9 & 25.3 & & 330.8 \\
45 & 595.2 & 27.5 & & 332.6 \\
\hline
\end{tabular}

\subsection{Surface Morphology}

\subsubsection{AFM analysis}

AFM micrographs of the CS surface after $6 \mathrm{~h}$ immersion time in the existence and nonexistence of the optimum dose of the studied $\mathrm{AJH}$ in $1.0 \mathrm{M} \mathrm{HCl}$ are given in Figure 10. In the absence of both $\mathrm{HCl}$ and inhibitor (Figure 10a) the surface appears to be smooth [47]. The AFM micrograph in the absence of A.J.H (Figure 10b) is characterized by a very rough electrode surface due to aggressive attack by the acid. However, in the attendance of $300 \mathrm{ppm}$ of AJH extract (Figure 10c), the AFM micrographs show remarkable progress in the surface morphology, which could be due to the adsorption and creation of protecting 
film by the AJH extract on the CS surface. The calculated average surface roughness with and without the AJH water extract are listed in Table 8. From this result, blank is the roughest one due to destructive of a metal surface by $\mathrm{HCl}$, "free" (coins in $\mathrm{HCl}$ ) is the lowest one and the "sample" (coins in the absence of $\mathrm{HCl}$ and extract) moderate in height [27].
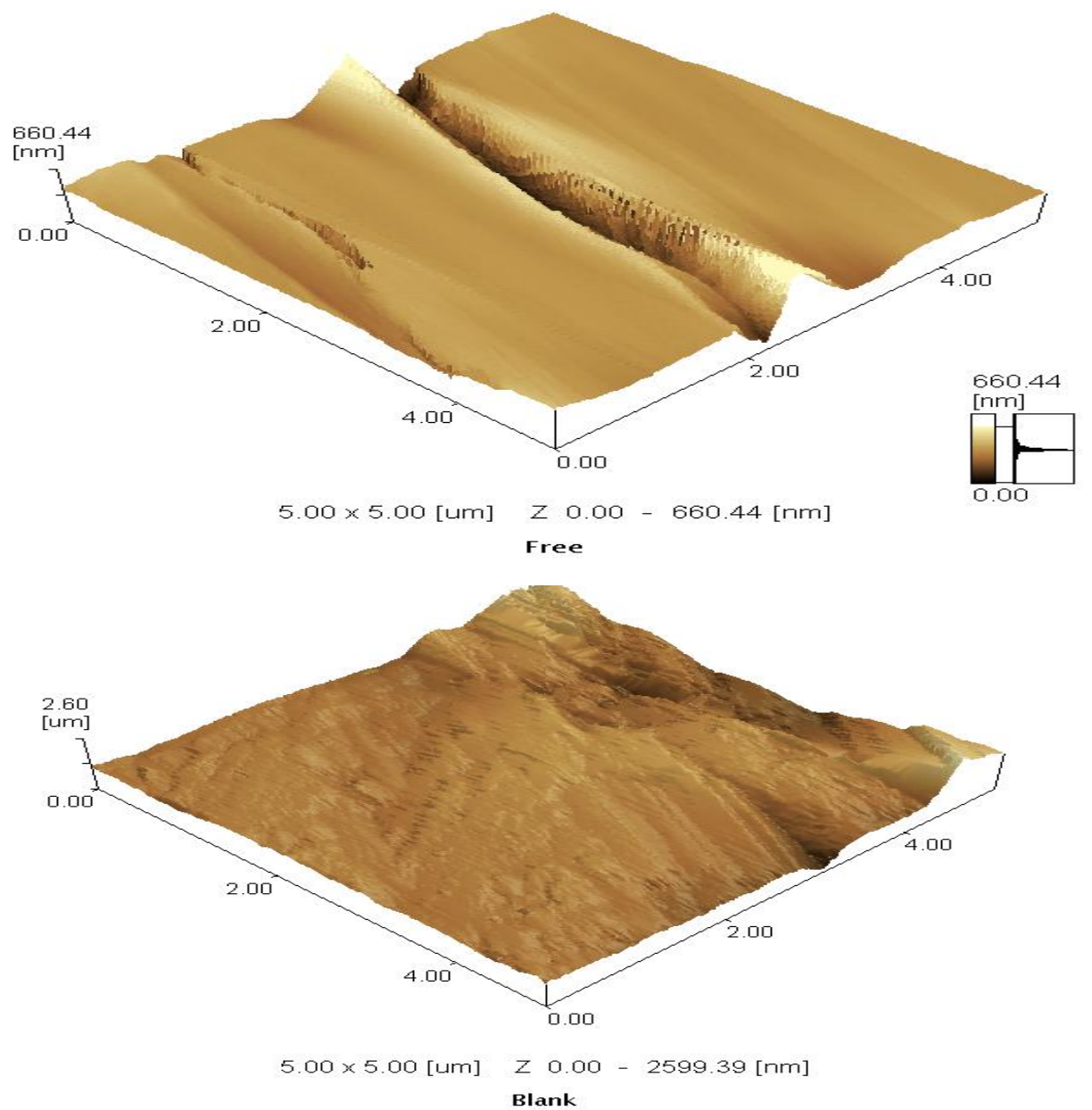

x)

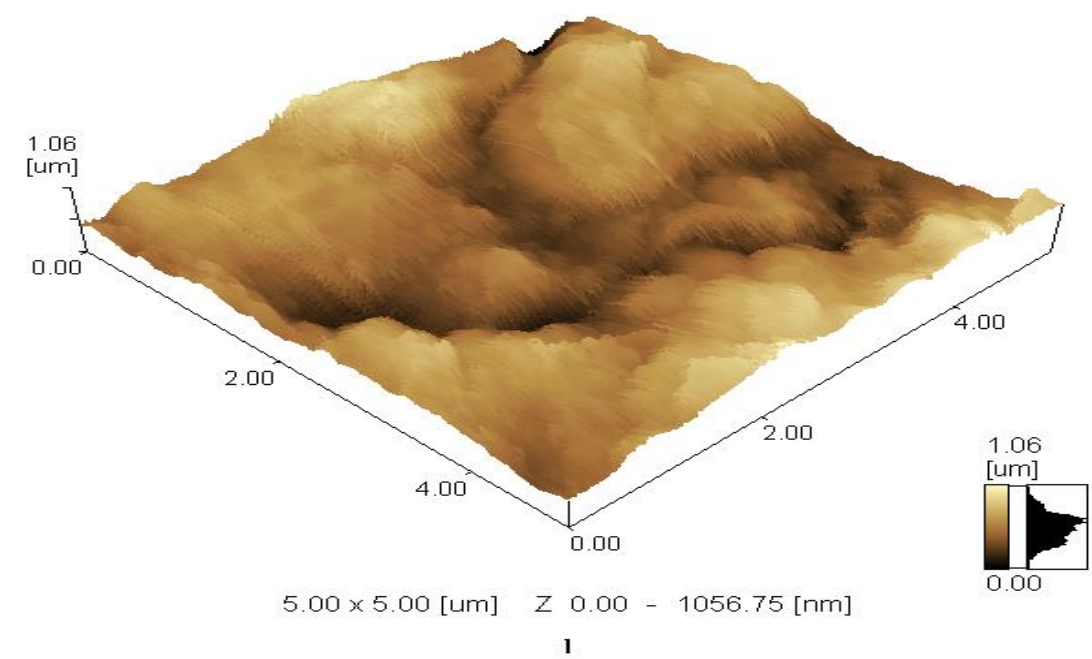

(b)

(c)

Figure 10. Micrograph of AJH a) "free"; b) in the absence of AJH extract; and c) in the presence of $300 \mathrm{ppm}$ AJH extract. 
Table 8. Variations in maximum height of particles in the surface of the CS without AJH extract as "blank", "free" ones and with 300 ppm of AJH extract.

\begin{tabular}{cccc}
\hline Statistics Value & Volume $\left[\boldsymbol{\mu m}^{3}\right]$ & Roughness $[\boldsymbol{\mu m}]$ & Height $[\boldsymbol{\mu m}]$ \\
\hline $\begin{array}{c}\text { Coins in } \mathrm{HCl} \\
\begin{array}{c}\text { Coins in } \mathrm{HCl} \text { and } \\
\text { extract }\end{array}\end{array}$ & 0.238 & 11.79 & 2.60 \\
$\begin{array}{c}\text { Coins in the absence of } \\
\mathrm{HCl} \text { and extract }\end{array}$ & 0.009 & 5.30 & 0.60 \\
\hline
\end{tabular}

\subsubsection{FT-IR spectroscopy analysis}

Adsorption is affected by the charge and the nature of the CS surface, chemical assembly of the extract and the kind of the electrolyte (corrosive medium) [48]. Chloride ions are first adsorbed on the CS surface and consequently, the metal surface becomes negatively charged. The molecules are made of the aromatic ring which contains $\pi$ electrons and the electron pairs of $\mathrm{N} \& \mathrm{O}$ atoms so it is easily protonated in $\mathrm{HCl}$ and the protonated molecules are physically adsorbed and then chemical adsorption appears also, so some of function groups disappear on CS surface.

Figure 11 compares the FT-IR spectrum of lyophilized AJH extract and molecules adsorbed on CS surface. Table 9 demonstrates the infrared absorption frequencies of different functional groups.

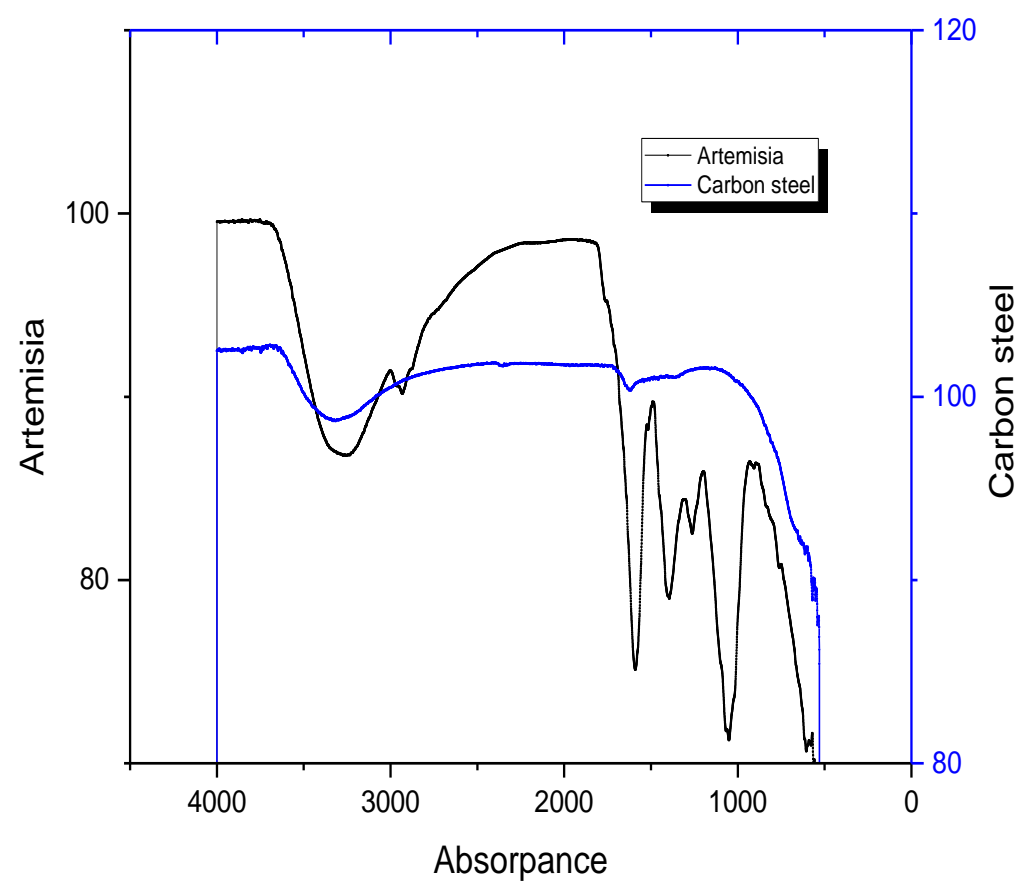

Figure 11. FT-IR spectrum of AJH extracts (black) and extracts adsorbed on the CS surface (blue). 
Table 9. Infrared absorption frequencies for the AJH extract and the surface of CS.

\begin{tabular}{|c|c|c|}
\hline \multirow{2}{*}{ Type of bond } & \multicolumn{2}{|c|}{ Wave number $\mathrm{cm}^{-1}$} \\
\hline & AJH extract & CS surface \\
\hline $\mathrm{O}-\mathrm{H}, \mathrm{C}-\mathrm{H}, \mathrm{N}-\mathrm{H}$ & 3272 & 3318 \\
\hline $\mathrm{C}-\mathrm{H}$ & 2932 & Hidden \\
\hline $\mathrm{C}=\mathrm{N}$ & 1590 & 1616 \\
\hline $\mathrm{C}=\mathrm{O}, \mathrm{C}-\mathrm{O}$ acid & 1262 & Hidden \\
\hline $\mathrm{C}-\mathrm{O}$ & 1067 & Hidden \\
\hline Aromatic & 1394 & 1457 \\
\hline
\end{tabular}

\subsubsection{SEM Studies}

Figures $12 \mathrm{a}-\mathrm{c}$ show the morphological differences between the specimen placed in $\mathrm{HCl}$ only, in optimum concentration of AJH extract and the clean CS only. The clean CS is the smoothest one (Figure 12a). The specimen in the acid medium has only been the most destructive one (Figure 12b). The sample with the optimum concentration reveals remarkable change in surface morphology in thickness and smoothness (Figure 12c) [49]. This is because the molecules adsorbed on CS surface protect the surface from destruction or corrosion [50].
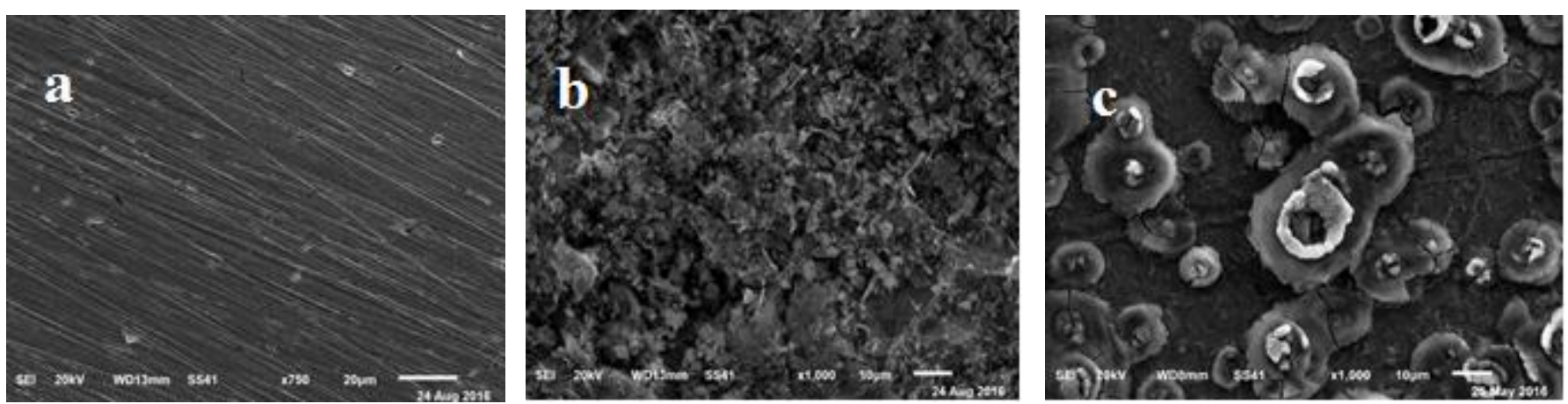

Figure 12. SEM micrographs of CS surface (a) before immersion in $1 \mathrm{M} \mathrm{HCl}$, (b) after $6 \mathrm{~h}$ immersion in $1 \mathrm{M} \mathrm{HCl}$ and (c) after $6 \mathrm{~h}$ immersion in $1 \mathrm{M} \mathrm{HCl}+300 \mathrm{ppm}$ of extract at $25^{\circ} \mathrm{C}$.

\subsection{Quantum chemical studies}

The computational study was done using Dmol3 program, which incorporates the Density functional theory (DFT) to investigate the interaction between the metal, and the inhibitor [51] reportedly isolated some chemical constituents from the Artemisia Judaica herbs extract (AJH), which included Naringin, Ellagic acid, Piperitone, Bronyl acetate and Terpinen-4-ol. Table 10 shows up the values obtained from DFT for the energy of HOMO $\left(E_{\mathrm{HOMO}}\right)$, the $E_{\mathrm{LumO}}, \Delta E$ and some other parameters. The $E_{\mathrm{HOMO}}$ is related to the electron 
donating capacity of the molecule. A higher value of $E_{\mathrm{HOMO}}$ is thus associated with the most effective inhibitor. On the other hand, $E_{\mathrm{LUMO}}$ is connected with the affinity of the molecule to accept electrons [52]. Thus, the lower value of $E_{\mathrm{LuMO}}$ implies better efficiency. The energy gap of a molecule $\Delta E$ is related to the hardness and softness of the molecule. Large value of energy gap implies that the molecule will need much energy to move from HOMO to the LUMO. Therefore, larger $\Delta E$ shows that the molecule is hard, while lower $\Delta E$ points towards the soft molecule [53]. From the results recorded in Table 10, it is evident that Ellagic acid is a more effective inhibitor than other components. From data in Table 10, if $\Delta N>0$, the electrons move to the metal surface from molecules, and if $\Delta N<0$, the electrons move from the metal to molecules [54], not only, but also the molecule would have higher electron-donating ability and better corrosion inhibition efficiency if $\Delta N<3.6$ [55]. The values of $\Delta N$ in Table 10 for these compounds are from 0.95 to 1.22 which are positive and are smaller than 3.6, demonstrating that these main compounds can provide their electrons to the iron, forming a coordinate bond. Figure 13 shows the geometric molecular structures, HOMO and LUMO of Naringin, Ellagic acid, Piperitone, Bronyl acetate and Terpinen-4-ol, respectively which support the computed result.

Table 10. The calculated quantum chemical parameters for Naringin, Ellagic acid, Piperitone Bronyl acetate and Terpinen-4-ol compounds.

\begin{tabular}{|c|c|c|c|c|c|c|}
\hline \multicolumn{2}{|r|}{ Parameter } & Naringin & $\begin{array}{l}\text { Ellagic } \\
\text { acid }\end{array}$ & Piperitone & $\begin{array}{l}\text { Bronyl } \\
\text { acetate }\end{array}$ & $\begin{array}{l}\text { Terpinen- } \\
\text { 4-ol }\end{array}$ \\
\hline \multirow{10}{*}{$\begin{array}{l}\text { Dmol3/ } \\
\text { B3LYP }\end{array}$} & $-E_{\text {номо }}(\mathrm{eV})$ & 4.969 & 4.086 & 4.917 & 4.917 & 4.917 \\
\hline & $-E_{\text {LUMO }}(\mathrm{eV})$ & 2.099 & 2.432 & 0.319 & 0.319 & 0.319 \\
\hline & $\Delta E(\mathrm{eV})$ & 2.87 & 1.654 & 4.598 & 4.598 & 4.598 \\
\hline & $\eta$ & 1.435 & 1.327 & 2.299 & 2.299 & 2.299 \\
\hline & $\sigma$ & 0.696 & 0.753 & 0.434 & 0.434 & 0.434 \\
\hline & $-\mathrm{Pi}$ & 3.534 & 3.759 & 2.618 & 2.618 & 2.618 \\
\hline & $\chi$ & 3.534 & 3.759 & 2.618 & 2.618 & 2.618 \\
\hline & $\Delta N(\mathrm{e})$ & 1.207 & 1.22 & 0.95 & 0.95 & 0.95 \\
\hline & $\mu$ (debyes) & 4.862 & 0.0115 & 2.3481 & 2.3481 & 2.3481 \\
\hline & $\begin{array}{c}\text { Molecular area } \\
\left(\AA^{2}\right)\end{array}$ & 519.556 & 262.730 & 198.623 & 198.623 & 198.623 \\
\hline
\end{tabular}


Figure 13. The optimized molecular structures, HOMO and LUMO of the inhibitor molecules using DMol3 schematic.

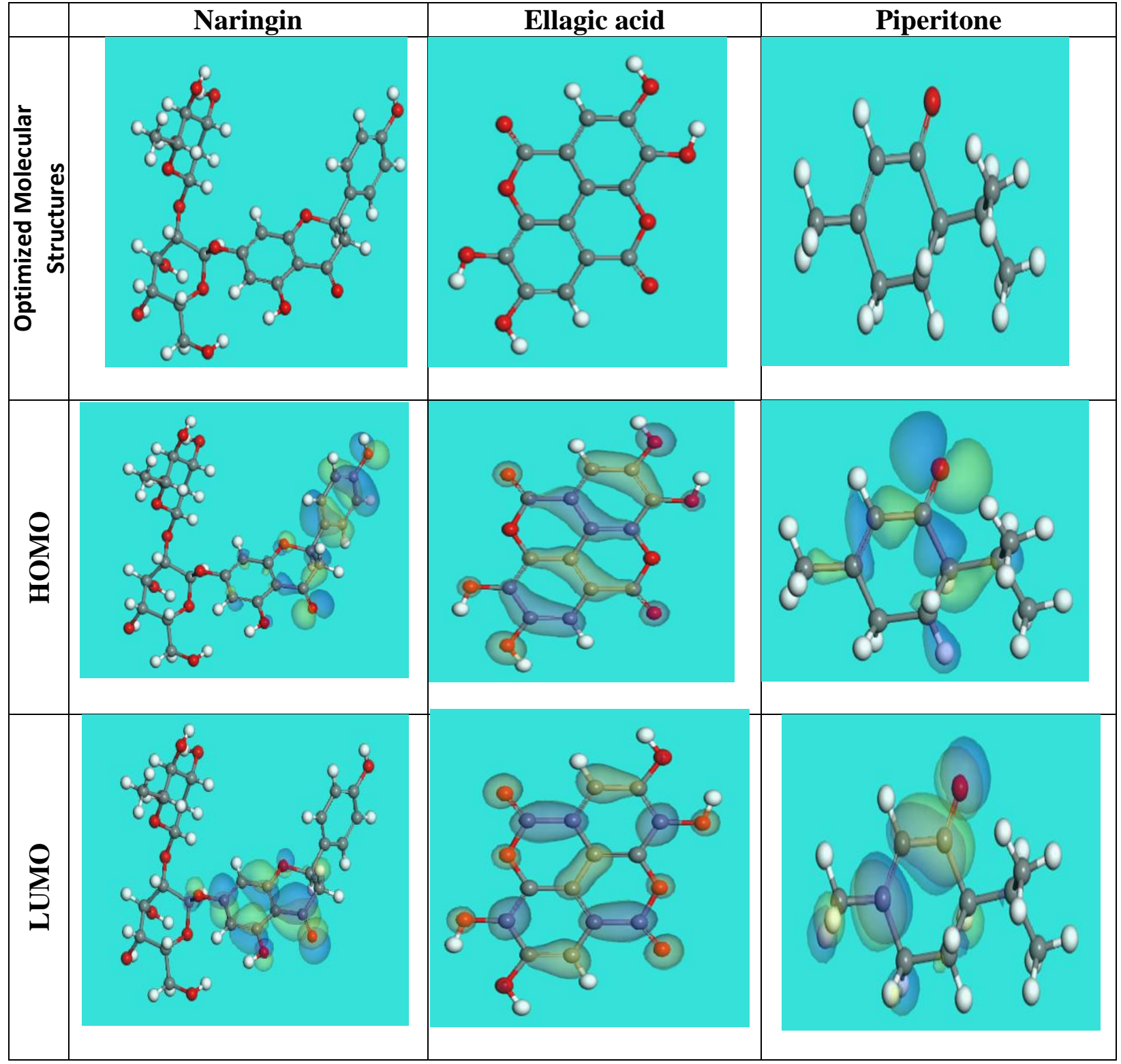

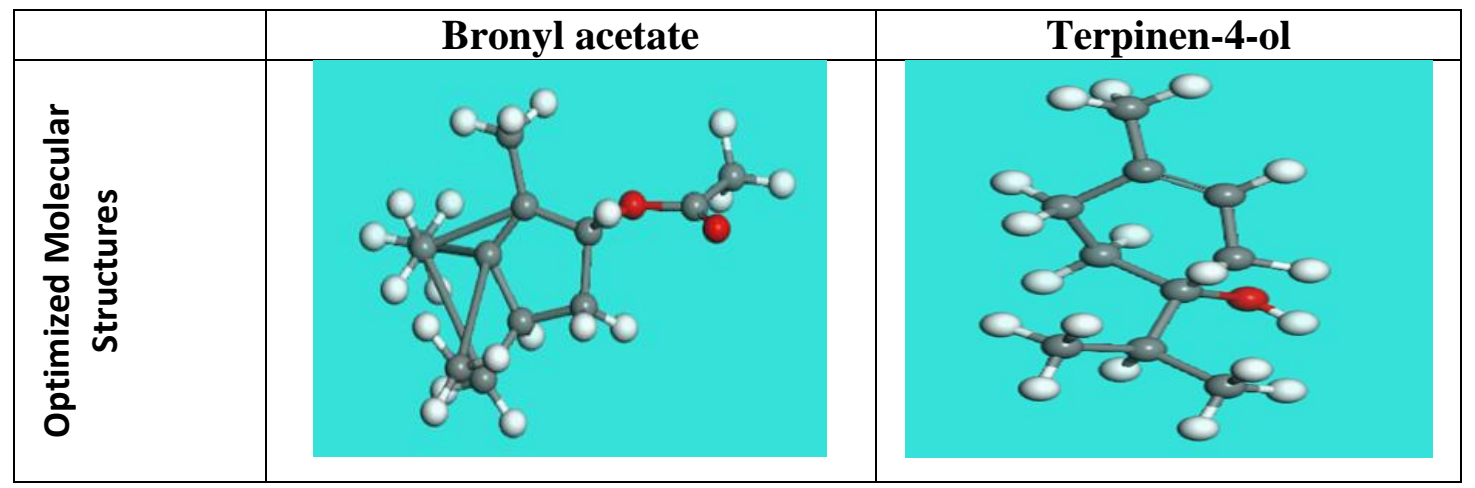




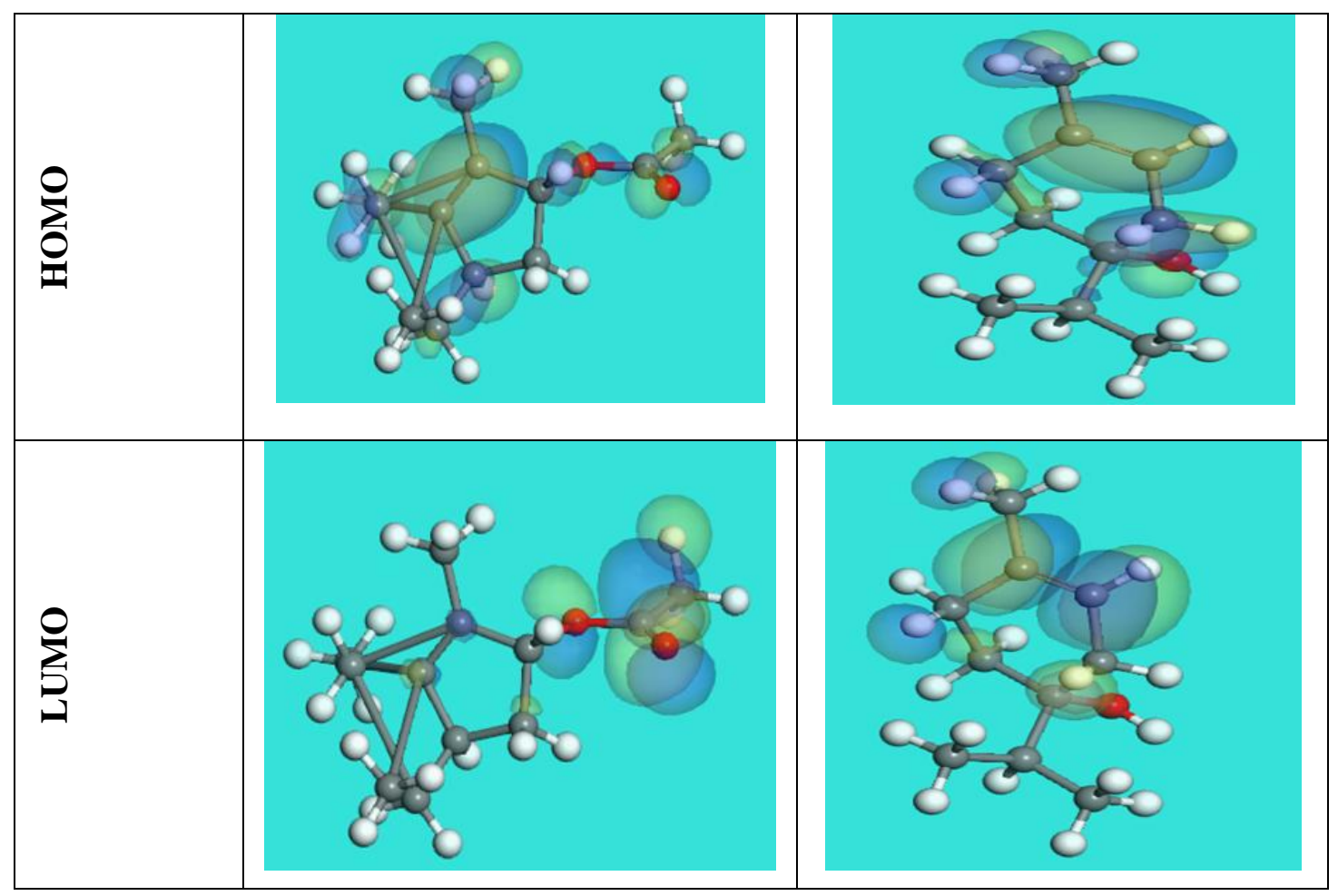

\section{Conclusions}

From previous tests the following conclusions can be drawn:

AJH extract displayed excellent corrosion hindrance for $\mathrm{CS}$ in $1.0 \mathrm{M} \mathrm{HCl}$. AJH extracts have corrosion inhibition percentage above $80 \%$ that refer to excellence in the inhibition. C.R values decrease with an increase in the concentration of AJH. The adsorption isotherm showed that the process obeys Langmuir adsorption isotherm. The spontaneous and endothermic behavior of the adsorption process has been demonstrated from the $\Delta G_{\text {ads }}^{0}, E_{\mathrm{a}}^{*}, \Delta H_{\text {ads }}^{0}$, and $\Delta S_{\text {ads }}^{0}$ data, not only that, but also both types of adsorption physical and chemical demonstrated. PP curves displayed that this extract acts as a mixed kind inhibitor. Surface examination (AFM, SEM and FTIR) demonstrated that the CS surface is covered by the existence of AJH extract.

\section{Reference}

1. G. Trabanelli, Corrosion, 1991, 47, 410-419. doi: 10.5006/1.3585271

2. A. Satapathy, G. Gunasekaran, S. Sahoo, K. Amit and P. Rodrigues, Corros. Sci., 2009, 51, 2848-2856. doi: $10.1016 /$ j.corsci.2009.08.016

3. V.V. Torres, R.S. Amado, C.F. de Sá, T.L. Fernandez, C.A. da Silva Riehl, A.G. Torres and E. D'Elia, Corros. Sci., 2011, 53, 2385-2392. doi: 10.1016/j.corsci.2011.03.021

4. L. Chauhan and G. Gunasekaran, Corros. Sci., 2007, 49, 1143-1161. doi: $\underline{10.1016 / j . c o r s c i .2006 .08 .012}$ 
5. M. Migahed, A. Abdul-Raheim, A. Atta and W. Brostow, Mater. Chem. Phys., 2010, 121, 208-214. doi: $10.1016 /$ j.matchemphys.2010.01.018

6. A. Fouda and A.H. Badr, Afr. J. Pure Appl. Chem., 2013, 7, 350-359. doi: 10.5897/AJPAC2013.0524

7. A.S. Abbas, É. Fazakas and T.I. Török, Int. J. Corros. Scale Inhib., 2018, 7, 38-47. doi: $10.17675 / 2305-6894-2018-7-1-3$

8. A.S. Fouda, S.A. Abd El-Maksoud, M.Sh. Zoromba and A.R. Ibrahim, Int. J. Corros. Scale Inhib., 2017, 6, 428-448. doi: 10.17675/2305-6894-2017-6-4-4

9. A. Peter and S.K. Sharma, Int. J. Corros. Scale Inhib., 2017, 6, 112-131. doi: 10.17675/2305-6894-2017-6-2-2

10. A.M. Al-Bonayan, Int. J. Res. Rev. Appl. Sci., 2015, 22, no. 2, 49-64.

11. J.C. da Rocha, J.A. d. C.P. Gomes and E. D'Elia, Corros. Sci., 2010, 52, 2341-2348.

12. A. Abdel-Gaber, B. Abd-El-Nabey and M. Saadawy, Corros. Sci., 2009, 51, 10381042. doi: $10.1016 /$ j.corsci.2009.03.003

13. A. Fouda, G. El-Ewady and A. Ali, Green Chem. Lett. Rev., 2017, 10, 88-100. doi: $\underline{10.1080 / 17518253.2017 .1299228}$

14. C. Kamal and M.G. Sethuraman, Ind. Eng. Chem. Res., 2012, 51, 10399-10407. doi: $\underline{10.1021 / i e 3010379}$

15. E. Oguzie, A. Onuchukwu, P. Okafor and E. Ebenso, Pigm. Resin Technol., 2006, 35, $63-70$.

16. A. Chetouani and B. Hammouti, Bull. Electrochem., 2003, 19, 23-25.

17. A. Fouda, K. Shalabi, G. Elewady and H. Merayyed, Int. J. Electrochem. Sci., 2014, 9, $7038-7058$.

18. A. Fouda, A. El-Khateeb, M. Ibrahim and M. Fakih, Nature and Science, 2015, 13, 71-82.

19. P. Goupy, M. Hugues, P. Boivin and M. Amiot, J. Sc. Food Agric., 1999, 79, 16251634. doi: 10.1002/(SICI)1097-0010(199909)79:12<1625::AID-JSFA411>3.0.CO;2-8

20. P. Mattila, J. Astola and J. Kumpulainen, J. Agric. Food Chem., 2000, 48, 5834-5841. doi: $10.1021 / \mathrm{jf000661f}$

21. G.M. Al-Senani, Int. J. Electrochem. Sci., 2016, 11, 291-302.

22. I. Obot and N. Obi-Egbedi, Corros. Sci., 2010, 52, 282-285.

23. I. Obot and N. Obi-Egbedi, Mater. Chem. Phys., 2010, 122, 325-328. doi: 10.1016/j.matchemphys.2010.03.037

24. I. Jevremović, M. Singer, S. Nešić and V. Mišković-Stanković, Corros. Sci., 2013, 77, 265-272. doi: 10.1016/j.corsci.2013.08.012

25. M. Prabakaran, S.H. Kim, V. Hemapriya and I.M. Chung, J. Ind. Eng. Chem., 2016,

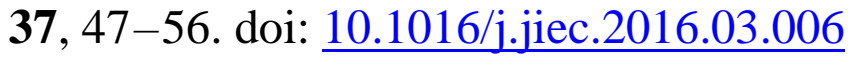

26. A. Singh and M. Quraishi, Res. Chem. Intermed., 2015, 41, 2901-2914. doi: 10.1007/s11164-013-1398-3

27. M. Yadav, R. Sinha, T. Sarkar, I. Bahadur and E.E. Ebenso, J. Mol. Liq., 2015, 212, 686-698. doi: 10.1016/j.molliq.2015.09.047 
28. M. Benabdellah, A. Aouniti, A. Dafali, B. Hammouti, M. Benkaddour, A. Yahyi and A. Ettouhami, Appl. Surf. Sci., 2006, 252, no. 23, 8341-8347. doi: 10.1016/j.apsusc. 2005.11.037

29. Shalabi, K., Y. Abdallah, and A. Fouda, Research on Chemical Intermediates, 41(7) (2015) 4687-4711. https://doi.org/10.1007/s11164-014-1561-5

30. T. Arslan, F. Kandemirli, E.E. Ebenso, I. Love and H. Alemu, Corros. Sci., 2009, 51, no. 1, 35-47. doi: $10.1016 /$ j.corsci.2008.10.016

31. T. Dob and C. Chelghoum, Flavour Fragrance J., 2006, 21, 343-347. doi: 10.1002/ ffj. 1641

32. K. Ferreira, R. Cordeiro, N. Nunes, H. Orofino, M. Magalhães, A. Torres and E. D'Elia, Int. J. Electrochem. Sci., 2016, 11, 406-418.

33. M. Morad, J. Appl. Electrochem., 1999, 29, 619-626.

34. M. Hegazy, A.A. Nazeer and K. Shalabi, J. Mol. Liq., 2015, 209, 419-427. doi: 10.1016/j.molliq.2015.05.043

35. J. Trinstancho-Reyes, M. Sanchez-Carrillo, R. Sandoval-Jabalera, V. Orozco-Carmona, F. Almeraya-Calderon, J. Chacon-Nava, J. Gonzalez-Rodriguez and A. MartinezVillafane, Int. J. Electrochem. Sci., 2011, 6, 419-431.

36. A. El-Askalany, S. Mostafa, K. Shalabi, A. Eid and S. Shaaban, J. Mol. Liq., 2016, 223, 497-508. doi: 10.1016/j.molliq.2016.08.088

37. C. Hsu, and F. Mansfeld, Corrosion, 2001, 57, 747-748. doi: 10.5006/1.3280607

38. D.K. Yadav, M. Quraishi and B. Maiti, Corros. Sci., 2012, 55, 254-266. doi: 10.1016/j.corsci.2011.10.030

39. K. Shalabi, Y. Abdallah and A. Fouda, Res. Chem. Inter., 2015, 41, 4687-4711. doi: 10.1016/j.polymer.2016.01.014

40. A. El-Etre and M. Abdallah, Corros. Sci., 2000, 42, 731-738. doi: 10.1016/S0010938X(99)00106-7

41. V.R. Saliyan and A.V. Adhikari, Bull. Mater. Sci., 2008, 31, 699-711. doi: 10.1007/ s12034-008-0111-4

42. M. Finsgar, Corros. Sci., 2013, 72, 82-89. doi: 10.1016/j.corsci.2013.03.011

43. A. Fouda, K. Shalabi and A. Idress, Int. J. Electrochem., 2014, 4, 5126-5154.

44. T. Zhao and G. Mu, Corros. Sci., 1999, 41, 1937-1944. doi: 10.1016/S0010938X(99)00029-3

45. G. Quartarone, M. Battilana, L. Bonaldo and T. Tortato, Corros. Sci., 2008, 50, 34673474. doi: $10.1016 /$ i.corsci.2008.09.032

46. A. Döner and G. Kardaş, Corros. Sci., 2011, 53, 4223-4232. doi: 10.1016/j.corsci.2011.08.032

47. P. Mourya, S. Banerjee and M. Singh, Corros. Sci., 2014, 85, 352-363. doi: 10.1016/j.corsci.2014.04.036

48. M. Jokar, T.S. Farahani and B. Ramezanzadeh, J. Taiwan Inst. Chem. Eng., 2016, 63, 436-452. doi: $10.1016 /$ j.jtice.2016.02.027 
49. M. Yadav, L. Gope, N. Kumari and P. Yadav, J. Mol. Liq., 2016, 216, 78-86. doi: 10.1016/j.molliq.2015.12.106

50. C. Verma, M. Quraishi and A. Singh, J. Mol. Liq., 2015, 212, 804-812. doi: 10.1016/j.molliq.2015.10.026

51. C.L. Lee, S.L. Lee, C.J. Chen, H.C. Chen and M.C. Kao, Molecules, 2016, 21, 745759.

52. F. Jensen, Introduction to Computational Chemistry, 2007, John Wiley \& Sons, Chichester.

53. E.E. Ebenso, I.B. Obot and L.C. Murulana, Int. J. Electrochem. Sci., 2010, 5, 15741586.

54. K. Khaled, Electrochim. Acta, 2010, 55, no. 22, 6523-6532. doi: 10.1016/j.electacta. $\underline{2010.06 .027}$ 